\title{
Implementasi Metode Waterfall Pada Aplikasi Perpustakaan Berbasis Web
}

\author{
Supriatiningsih \\ Sistem Informasi, Universitas Bina Sarana Informatika \\ supriatiningsih.stq@bsi.ac.id
}

\begin{abstract}
The library is part of the source of educational facilities because it provides additional information or knowledge for students and also for the general public. The demand for library services quickly is a top priority in the information field. The variety of data that is processed by libraries, as well as people who are increasingly intelligent in choosing and using library services, make these institutions have to think of appropriate solutions. At this time in processing data in the library is still using a manual system. Therefore a system is needed that can facilitate library processing data and facilitate library members or the public in obtaining information. The development of technology is increasing, so from the problem it is proposed that there is a change in the old system into a new system with web-based computer technology. The method used in the development of this software uses the Waterfall Model which is a systematic development model. Data collection methods that the authors use to collect data needed in this paper are: Observation, interview methods, and library methods. Through a computer connected to the internet network users can search and get various information, anywhere and anytime by accessing the website. With this system, it is expected to be able to overcome the various needs of users to obtain information and facilitate librarians in processing library data.
\end{abstract}

Keywords: Information Systems, Library, Website

\begin{abstract}
Abstrak - Perpustakaan merupakan bagian dari sumber sarana pendidikan karena memberikan tambahan informasi atau pengetahuan bagi siswa dan juga bagi masyarakat umum. Permintaan pelayanan perpustakaan secara cepat merupakan prioritas utama dari bidang informasi. Beragamnya data yang diolah oleh perpustakaan, serta masyarakat yang semakin cerdas dalam memilih dan menggunakan jasa perpustakaan membuat institusi tersebut harus memikirkan solusi yang tepat. Pada saat ini dalam pengolahan data di perpustakaan masih menggunakan sistem manual. Maka dari itu dibutuhkan sistem yang dapat mempermudah perpustakan dalam mengolah data serta mempermudah anggota perpustakaan atau masyarakat dalam memperoleh informasi. Perkembangan teknologi yang semakin meningkat, maka dari permasalahan tersebut diusulkan adanya perubahan sistem lama kedalam sistem yang baru dengan teknologi komputer berbasis web. Metode yang digunakan pada pengembangan perangkat lunak ini menggunakan Model Waterfallyaitu model pengembangan yang sifatnya sistematis. Metode pengumpulan data yang penulis gunakan untuk mengumpulkan data-data yang di perlukan dalam penulisan ini yaitu: Observasi, metode wawancara, dan metode pustaka. Melalui komputer yang terkoneksi dengan jaringan internetuser dapat mencari dan mendapatkan berbagai informasi, dimana saja dan kapan saja dengan mengakses website. Dengan adanya sistem ini, diharapkan mampu mengatasi berbagai kebutuhan user untuk memperoleh informasi serta mempermudah pustakawan dalam mengolah data perpustakaan.
\end{abstract}

Kata Kunci : Sistem Informasi, Perpustakaan, Website 


\section{A. PENDAHULUAN}

Perpustakaan merupakan bagian dari sumber sarana pendidikan, karena dapat memberikan tambahan informasi atau pengetahuan bagi siswa dan juga bagi masyarakat umum. Permintaan pelayanan perpustakaan secara efektif dan cepat merupakan prioritas utama dari badan pelayanan umum di bidang informasi. Perpustakaan pun harus bisa melayani masyarakat dengan baik. Dengan beragamnya judul buku, penulis, topik serta masyarakat yang semakin cerdas dalam melilih dan menggunakan jasa perpustakaan membuat institusi tersebut harus semakin memikirkan jalan keluar yang baik.

Menurut (A.S Rosa dan M. Shalahuddin, 2013) "Model Pengembangan air terjun (waterfall) sering juga disebut model sekuensial linier (sequential linear) atau alur hidup klasik (classic life cycle). Diharapkan dengan menggunakan metode ini bisa menghasilkan suatu aplikasi yang tepat guna.

Teknologi informasi merupakan hal yang sangat dibutuhkan dalam kehidupan manusia. Seiring berjalanya waktu fungsi komputer semakin hari semakin meningkat. Melalui komputer, manusia juga dapat belajar mengenai internet. Internet merupakan jendela informasi yang sangat luas di dunia, informasi apapun dapat diperoleh melalui internet. Ketika menggunakan internet penggunapun dapat mengakses website. Website merupakan halaman informasi yang dapat diakses siapa saja dan kapan saja selama terkoneksi dengan jaringan internet. melalui website pengguna dapat mencari, dan mendapatkan berbagai informasi.

Besarnya minat untuk mendapatkan informasi dan peminjaman buku diperpustakaan memunculkan gagasan baru bagi institusi tersebut agar dapat dengan cepat, efektif dan efisien dalam melayani permintaan jasa. Selama ini sistemdan administrasi pelayanan dan pengolahan data di perpustakan tersebut masih dirasakan terlalu manual, sehingga dibutuhkan suatu sistem yang tepat sebagai penunjang mutu pelayanan yang efektif dan cepat. Berdasarkan permasalahan yang ada maka diusulkan adanya pembaruan sistem lama kedalam sistem yang baru dengan teknologi komputer berbasis web.

\section{B. TINJAUAN PUSTAKA}

1. Sistem

Menurut McLeod dalam (Yakub, 2012) mengatakan bahwa,"Sistem adalah sekelompok elemen-elemen yang terintegrasi dengan tujuan yang sama untuk mencapai tujuan".

\section{Informasi}

Menurut Gordon B. Davis dalam (Paryati dan Yosef Murkaya. KA, 2007) "Informasi merupakan data yang telah diolah menjadi bentuk yang berguna bagi penerimanya dan nyata, berupa nilai yang dapat dipahami di dalam keputusan sekarang maupun masa depan".

\section{Sistem Informasi}

Menurut O'Brian dalam (Yakub, 2012) 'Sistem informasi merupakan kombinasi teratur dari orang-orang, perangkat keras (hardware), perangkat lunak (software), jaringan komunikasi, dan sumber daya data yang mengumpulkan, mengubah, dan menyebarkan informasi dalam sebuah organisasi”.

\section{Perpustakaan}

Menurut (Supriyanto, 2008) "Perpustakaan adalah institusi yang menyediakan koleksi bahan pustaka tertulis, tercetak dan terekam sebagai pusat sumber informasi yang diatur menurut sistem aturan dan didayagunakan untuk keperlukan pendidikan, penelitian serta rekreasi intelektual bagi masyarakat". Berikut merupakan tugas pokok perpustakaan:

a. Menghimpun bahan pustaka yang meliputi buku dan nonbuku sebagai sumber informasi.

b. Mengolah dan merawat pustaka.

c. Memberikan layanan bahan pustaka. 


\section{Internet}

Menurut (Sibero, 2013) mendefinisikan bahwa, "Internet adalah jaringan komputer yang menghubungkan antar jaringan secara global, internet dapat juga disebut jaringan dalam suatu jaringan yang luas". seperti halnya jaringan komputer lokal maupun jaringan komputer area. Internet juga menggunakan protokol komunikasi yang sama yaitu TCP/IP (Transmission Control Protocol/ Intrnet Protocol).

\section{Website}

Menurut (Puspitosari, 2010) menjelaskan bahwa, "Website adalah halaman informasi yang disediakan melalui jalur internet sehingga bisa diakses diseluruh dunia, selama terkonesi dengan internef'. Secara garis besar, website digolongkan menjadi tiga jenis yaitu: website Statis, website Dinamis, website Interaktif.

7. HTML (Hypertext Markup Language),

Menurut (Nugroho, 2008) "HTML (Hypertext Markup Language) merupakan sebuah bahasa Scripting yang berguna untuk menulis halaman web. Pada halaman web, HTML dijadikan sebagai Bahasa Script dasar yang berjalan bersama berbagai bahasa Scripting Pemrograman lainya".

\section{PHP (Hypertext Preprocessor)}

Menurut (Kadir, 2008) "PHP merupakan singkatan dari Hypertext Preprocessor. PHP merupakan bahasa berbentuk skrip yang ditempatkan dalam server dan diproses di server. Hasilnya yang dikirimkan ke klien tempat pemakai menggunakan browser".

9. JavaScript.

Menurut (Kadir, 2009) "JavaScript adalah bahasa skrip (bahasa yang kodenya ditulis menggunakan teks biasa) yang ditempelkan pada dokumen HTML dan diproses pada sisi klien". Dengan adanya bahasa ini, kemampuan dokumen HTML menjadi lebih luas. Selain itu, dengan menggunakan JavaScript juga dimungkinkan untuk mengimplementasikan tugas yang bersifat interaktif tanpa berhubungan dengan server.

\section{0. jQuery}

Menurut (Sigit W., 2011) "jQuery adalah library kumpulan kode JavaScript siap pakai". Keunggulan menggunakan jQuery dibandingkan dengan javascript standar, yaitu menyederhanakan kode dengan javascript dengan cara memanggil fungsi-fungsi yang disediakan oleh jQuery.

\section{CSS}

Menurut (Saputra, 2012) "CSS atau yang memiliki kepanjangan Cascading Style Sheet, merupakan suatu bahasa pemprograman web yang digunakan untuk mengendalikan dan membangun berbagai komponen dalam web sehingga web akan rapih, terstruktur dan beragam". CSS difungsikan sebagai penopang atau pendukung, dan pelengkap dari file html yang berperan dalam penataan kerangka dan layout. CSS mampu platform, maksudnya dapat dijalankan pada berbagai macam sistem operasi dan web browser. Secaraumum yang dilakukan oleh CSS adalah pengaturan layout, kerangka, teks, gambar, warna, tabel, spasi dan lain sebagainya.

12. MySQL

Menurut (Nugroho, 2008) "MySQL merupakan database yang paling digemari dikalangan Programmer Web, dengan alasan bahwa program ini merupakan database yang sangat kuat dan cukup stabil untuk digunakan sebagai media penyimpan data. Sebagai sebuah databaseserver yang mampu untuk memanajemn dengan baik".

\section{PHP MyAdmin}

Menurut (Nugroho, 2008) "phpmyadmin adalah suatu aplikasi Open Sorce yang berbasis web, aplikasi ini dibuat menggunakan program PHP, fungsi dari aplikasi ini adalah untuk 
mengakses database MySQL". Dengan adanya aplikasi ini akan sangat mempermudah dan mempersingkat kerja dalam mengolah database.

\section{Struktur Navigasi}

Menurut (Sutopo, 2007) beberapa desainer web menggunakan teknik yang biasa seperti dalam pengembangan multimedia pada umumnya yaitu storyboarding. Pertama-tama pembuatan diagram untuk bermacam-macam halaman, seperti storyboarding pembuatan film dan video, kemudian hubungan detail yang diperlukan antara halaman-halaman secara keseluruhan. Dalam pengembangan web, terdapat beberapa model navigasi dasar, yang harus dikenal dengan baik oleh desainer, karena setiap model memberikan solusi untuk kebutuhan yang berbeda. Macam-macam struktiur navigasi:Linier Navigation Model, Hierarchical model, Spoke-and-hub Model,dan Full Web Model

\section{Entity Relationship Diagram (ERD)}

Menurut (A.S Rosa dan M. Shalahuddin, 2013) "Entity Relationship Diagram (ERD) merupakan pemodelan awal basis data yang dikembangkan berdasarkan teori himpunan dalam bidang matematika untuk pemodelan basis data relasional". ERD memiliki beberapa aliran notasi seperti notasi Chen (dikembangkan oleh Peter Chen), Barker (dikembangkan oleh Richard Barker, lan Palmer, Harry Ellis), notasi Crow's Foot, dan beberapa notasi lain. Namun yang banyak digunakan adalah notasi dari Chen.

\section{Black-box Testing}

Menurut (A.S Rosa dan M. Shalahuddin, 2013) menjelaskan bahwa, "Pengujian adalah satu set aktifitas yang direncanakan dan sistematis untuk menguji atau mengevaluasi kebenaran yang diinginkan".

Menurut (A.S Rosa dan M. Shalahuddin, 2013) mendefinisikan, "Black-box testing (pengujian kotak hitam) yaitu pengujian perangkat lunak dari segi spesifikasi fungsional tanpa menguji desain dan kode program". Pengujian yang dimaksud untuk mengetahui apakah fungsi-fungsi, masukan, dan keluaran dari perangkat lunak sesuai dengan spesifikasi yang dibutuhkan.

\section{METODE PENELITIAN}

Metode penelitian dan teknik pengumpulan data yang digunakan untuk penyusunan adalah:

1. Metode yang digunakan pada pengembangan perangkat lunak ini menggunkana model waterfall menurut (A.S Rosa dan M. Shalahuddin, 2013) yang terbagi menjadi lima tahapan yaitu
a. Analisa Kebutuhan
Pada tahap ini penulis melakukan analisa kebutuhan dengan melakukan riset pada perpustakaan. Dari hasil riset diperoleh kebutuhan-kebutuhan y ang diperlukan dalam pembuatan aplikasi ini.
b. Desain
Dalam tahap ini dilakukan desain sistem yang difokuskan pada empat atribut yaitu struktur data, aritektur perangkat lunak, rancangan antarmuka dan prosedur pengkodean.
c. Pembuatan Kode Program
Pada tahap ini, desain diterapkan ke dalam bentuk serangkaian kode desain. Kode- kode tersebut di susun, sehingga membentuk suatu program berdasarkan desain yang telah di buat.
d. Pengujian
Setelah program selesai di buat, maka selanjutnya proses pengujian. Tahap ini dilakukan guna mengetahui dan meminimalisir kesalahan (error) agar hasil keluaran yang ditampilkan dapat sesuai dengan keingian.

e. Pemeliharaan 
Dalam tahap ini, program sudah dapat digunakan. Kemudian dilakukan pengecekan dan evaluasi secara rutin dengan rentang waktu yang sudah ditentukan. Dapat dimungkinkan terdapat penambahan, pengurangan atau pengubahan beberapa desain dan struktur program.

2. Teknik Pengumpulan Data

Teknik pengumpulan data yang digunakan penulis dalam melakukan pengumpulan data ini adalah:

a. Observasi

Pengumpulan data dan informasi yang dilakukan dengan cara melakukan penelitian pada perpustakaan serta mengamati sistem yang sedang berjalan di perpustakaan tersebut.

b. Wawancara

Pengumpulan data dengan cara melakukan dialog secara langsung dengan pustakawan yang bersangkutan dalam memberikan keterangan terhadap informasi mengenai perpustakaan.

c. Studi Pustaka

Dalam metode ini penulis melengkapi data-data yang diperoleh dengan membaca buku dan browsing di internet. Buku dan data-data tersebut digunakan sebagi bahan referensi bagi penulis.

\section{HASIL PEMBAHASAN}

1. Analisa Kebutuhan

Analisa kebutuhan merupakan sebuah proses untuk mendapatkan informasi apa saja yang bisa dilakukan oleh pustakawan, pengunjung, dan anggota perpustakaan serta kebutuhan-kebutuhan yang diperlukan dalam pembuatan website ini.

a. Analisa kebutuhan pengguna

Dalam website Perpustakaan ini terdapat 2 macam pengguna yaitu:

1) Pustakawan

Pustakawan merupakan pengguna yang dapat melakukan pengolahan data. Baik itu berhubungan dengan website seperti menambah, mengubah dan menghapus konten yang ada di website maupun melakukan kegiatan yang berkaitan dengan kegiatan perpustakaan. Beberapa yang dibutuhkan oleh pustakawan antara lain:

a) Pustakawan membutuhkan akses untuk mengelola halaman website.

b) Pustakawan membutuhkan sistem yang dapat mengelola data mengenai koleksi buku, koleksi e-book, kategori buku, daftar anggota dan proses peminjaman dan pengembalian buku.

c) Pustakawan membutuhkan informasi mengenai peminjaman dan pengembalian buku.

d) Pustakawan membutuhkan sistem yang dapat mengelola pendaftaran anggota.

e) Pustakawan membutuhkan sistem untuk absensi kunjungan.

f) Pustakawan membutuhkan sistem yang dapat mencetak semua laporan dari setiap data seperti data pengembalian, peminjaman, daftar koleksi buku, daftar anggota, dan laporan mengenai pemasukandari denda setiap anggota.

2) Pengunjung

Pengunjung merupakan pengguna yang dapat mengakses halaman utama web ini. Berikut beberapa kebutuhan pengunjung diantaranya:

a) Pengunjung membutuhkan informasi yang ada di website ini.

b) Pengunjung membutuhkan informasi mengenai daftar buku yang ada di perpustakaan. Baik itu koleksi buku lama, buku terbaru dan buku terpopuler.

c) Pengunjung membutuhkan tambahan pengetahuan melaui sarana e-book. 
d) Penggunjung membutuhkan layanan untuk absensi kunjungan perpustakaan.

e) Pengunjung apabila sudah menjadi anggota perpustakaan membutuhkan informasi mengenai status peminjaman buku dan informasi mengenai denda yang harus dibayarkan.

b. Analisa Kebutuhan Sistem

Beberapa kebutuhan sistem yang ada di website perpustaan, di antaranya:

1) Pengolahan data

Dalam website perpustakaan pada, terdapat beberapa data yang akan dikelola, diantaranya:

a) Data profil berupa sejarah dan struktur organisasi perpustakaan

b) Data anggota perpustakaan yang berisi informasi mengenai anggota yang telah terdaftar

c) Data website yang berisi informasi mengenai koleksi buku perpustakaan.

d) Data website yang berisi informasi mengenai koleksi e-book perpustakaan

e) Data transaksi mengenai informasi peminjaman dan pengembalian buku.

f) Data absen kunjungan perpustakaan yang berisi informasi mengenai daftar pengunjung perpustakaan.

Pembuatan laporan dari setiap data seperti tarnsaksi peminjaman buku, pengembalian buku, total biaya yang di peroleh dari denda pengembalian buku dalam periode tertentu

2) Hak Akses

Hak akses yang terdapat pada website ini dibagi menjadi dua bagian, yaitu:

a) Pustakawan

a) Halaman kelola website

b) Halaman kelola anggota

c) Halaman kelola koleksi buku perpustakaan

d) Halaman kelola e-book

e) Halaman kelola transaksi peminjaman dan pengembalian buku

f) Halaman kelola pustakawan

g) Halaman kelola buku tamu

h) Halaman kelola laporan setiap data (peminjaman, pengembalian, denda, daftar kunjungan) pada periode tertentu.

i) Halaman pengaturan

b) Pengunjung

a) Halaman depan

b) Halaman profil

c) Halaman buku

d) Halaman e-book

e) Halaman absen kunjungan

f) Halaman anggota

g) Halaman tata tertib

h) Halaman buku tamu

i) Jika pengunjung sudah taerdaftar menjadi anggota perpustakaan, maka anggota dapat mengakses status peminjaman buku.

c. Keamanan 
Website perpustakaan ini membutuhkan sistem keamanan agar sistem berkerja. Selain itu, sistem keaman juga mencegah serangan dari pihak yang akan menggangu berjalannya sistem. Beberapa sistem keamanan yang dibutuhkan antara lain:

a. Password yang di gunakan untuk login dienkripsi agar tidak terbaca oleh pihak luar.

b. Terdapat sistem untuk ganti password pada setiap pustakawan.

2. Rancangan Antar Muka

Untuk memudahkan dalam perancangan web ini, maka rancangan dibuat harus digambar terlebih dahulu. Hal ini dimaksudkan agar memperjelas dan memudahkan dalam perancanga tampilan website. Rancangan tampilan website Perpustakaan yaitu

a. Rancangan Antar Muka Halaman Pustakawan

Berikut adalah salah satu contoh rancangan antarmuka halaman pustakawan. Halaman ini muncul ketika pustakawan sudah melakukan login. Halaman pustakawan adalah halaman yang digunakan untuk mengelola data perpustakaan dan isi dari website.

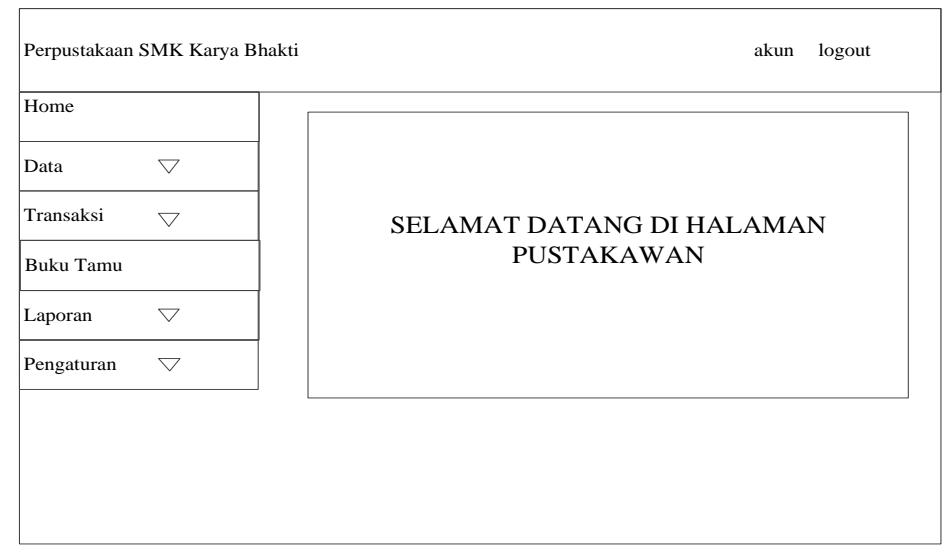

Gambar 1 Rancangan Antar Muka Halaman Pustakawan

b. Rancangan Antarmuka Halaman utama website Pengnjung.

Halaman utama website adalah tampilan awal ketika pengguna mengakses alamat websitePerpustakaan. Berikut adalah salah satu contoh halaman pengunjung.

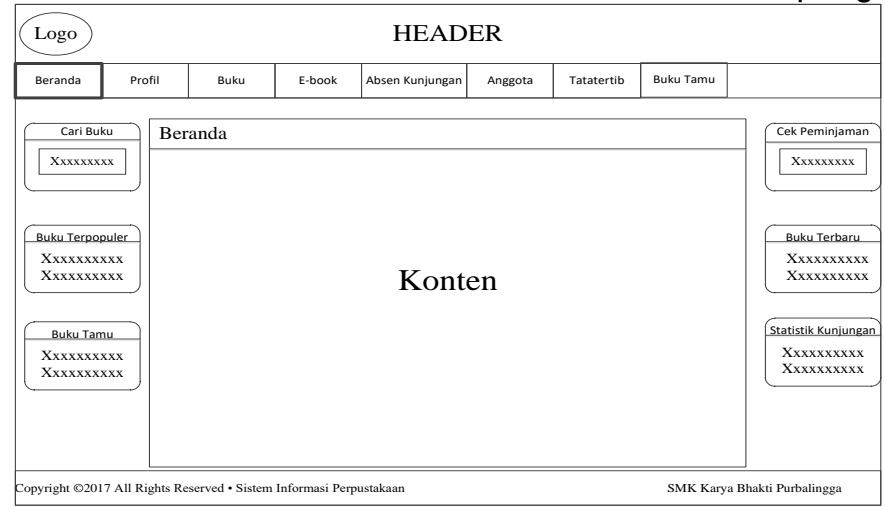

Gambar 2. Rancangan Antarmuka Halaman utama website

\section{Rancagan Basis Data}

Rancangan website Perpustakaan, yang terdiri dari entitas dan relasi menghasilkan pemetaan tabel-tabel yang digambarkan dengan Entity Relationship Diagram (ERD) dan Logical Relation Structure (LRS). 
IJSE - Indonesian Journal on Software Engineering, Vol.6, No. 1, Juni 2020, 83-93

pISSN: 2461-0690 I elSSN: 2714-9935

a. Entity Relationship Diagram (ERD)

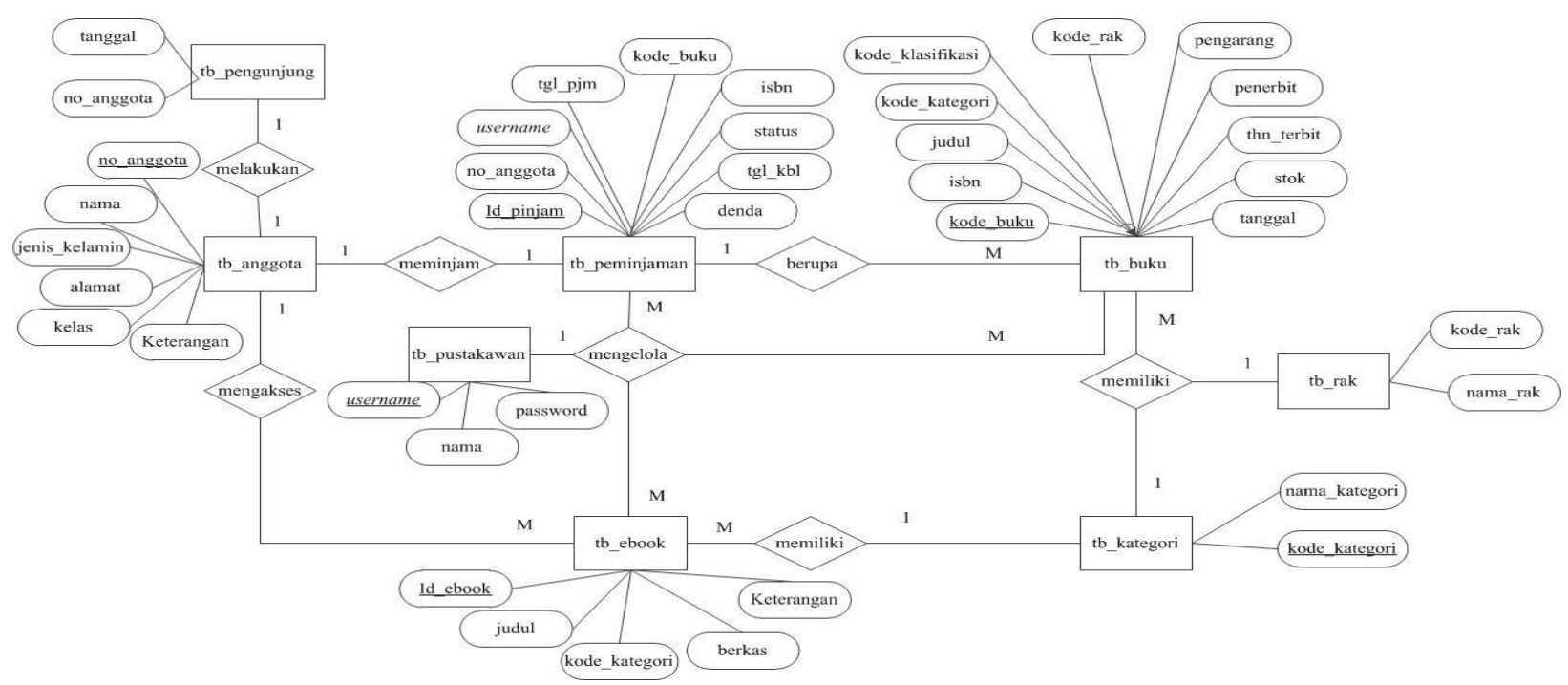

Gambar 3. Entity Relationship Diagram (ERD)

b. Logical Relation Structure (LRS).

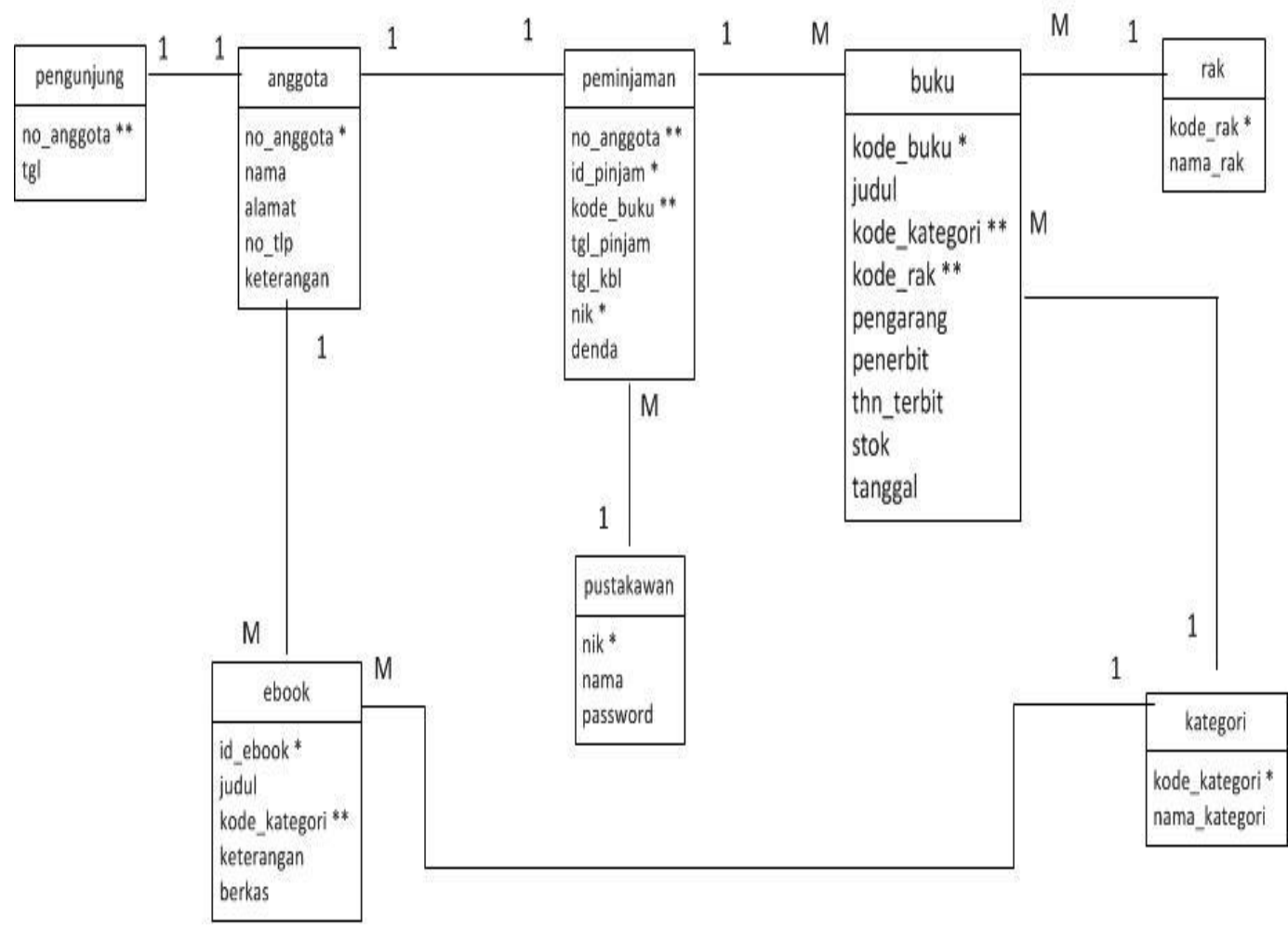

Gambar4. Logical Relation Structure (LRS).

4. Rancangan Struktur Navigasi

ejournal.bsi.ac.id/ejurnal/index.php/ijse Copyright (C Universitas Bina Sarana Informatika 
Agar mempermudah dalam merancanga sebuah web, maka perlu menggambarkan struktur navigasi terlebih dahulu. Hal ini bertujuan untuk memperjelas pada saat merancang tampilan web.

a. Rancangan Struktur Navigasi Pustakawan

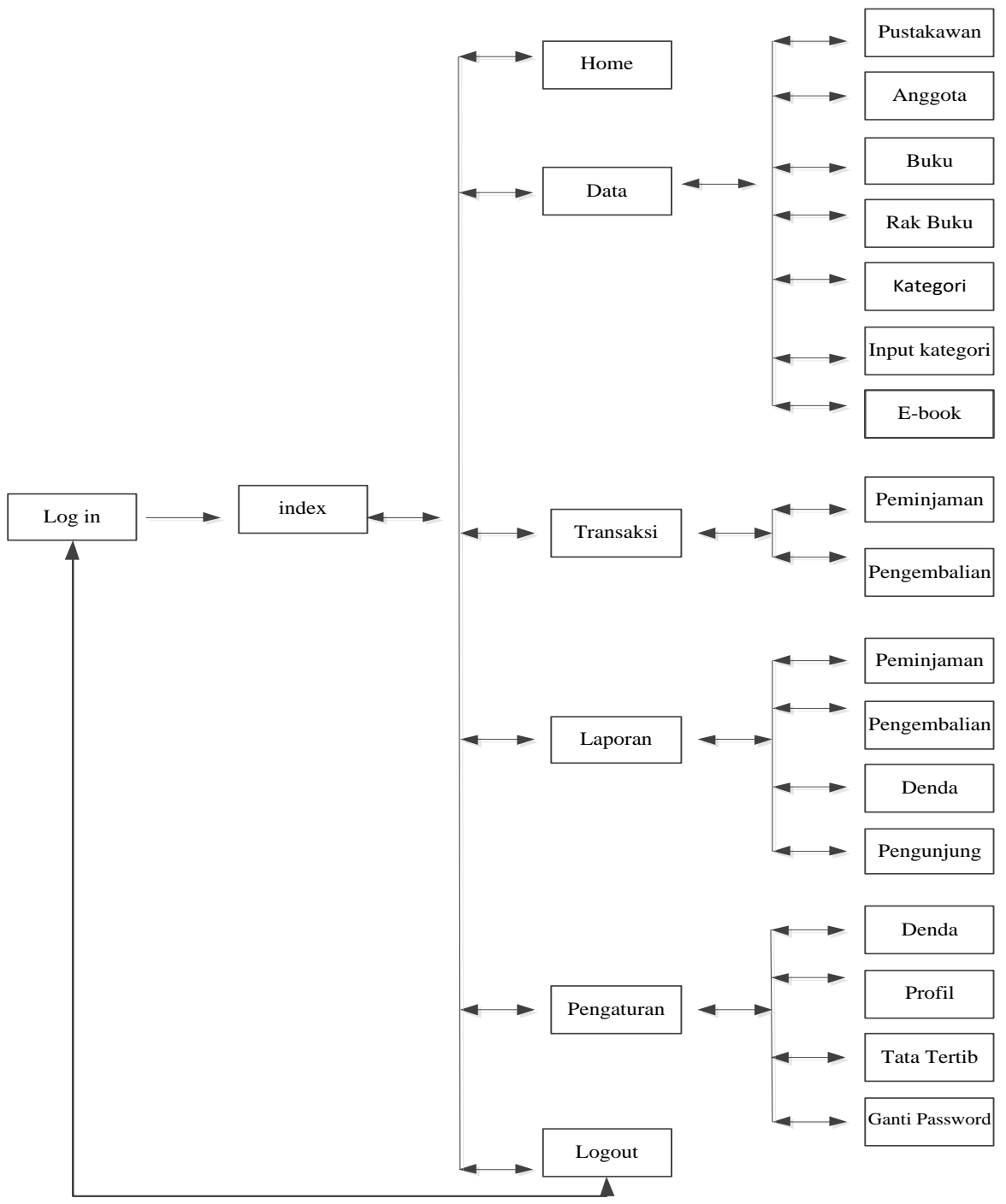

Gambar 5. Struktur Navigasi Pustakawan

b. Rancangan Struktur Navigasi Pengunjung

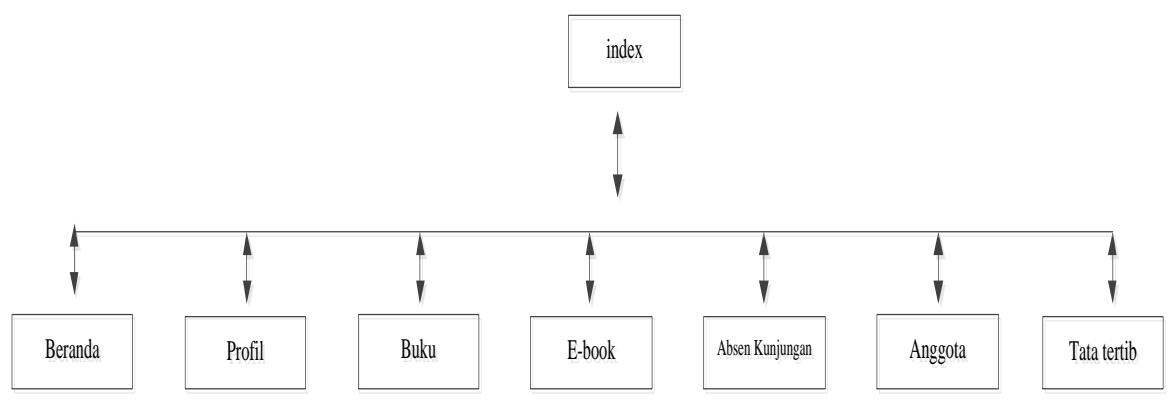

Gambar 6. Struktur Navigasi Pengunjung 
5. Implementasi

Implementasi rancangan antar muka merupakan hasil dari rancangan antar muka yang dirancang sebelum sebuah website dibuat. Berikut implementasi rancangan antarmuka dari beberapa halaman.

a. Halaman Pustakawan

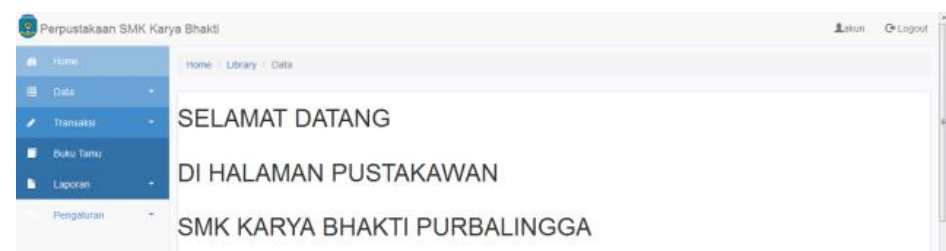

Gambar 7. Implementasi Halaman Pustakawan

b. Halaman Utama Website

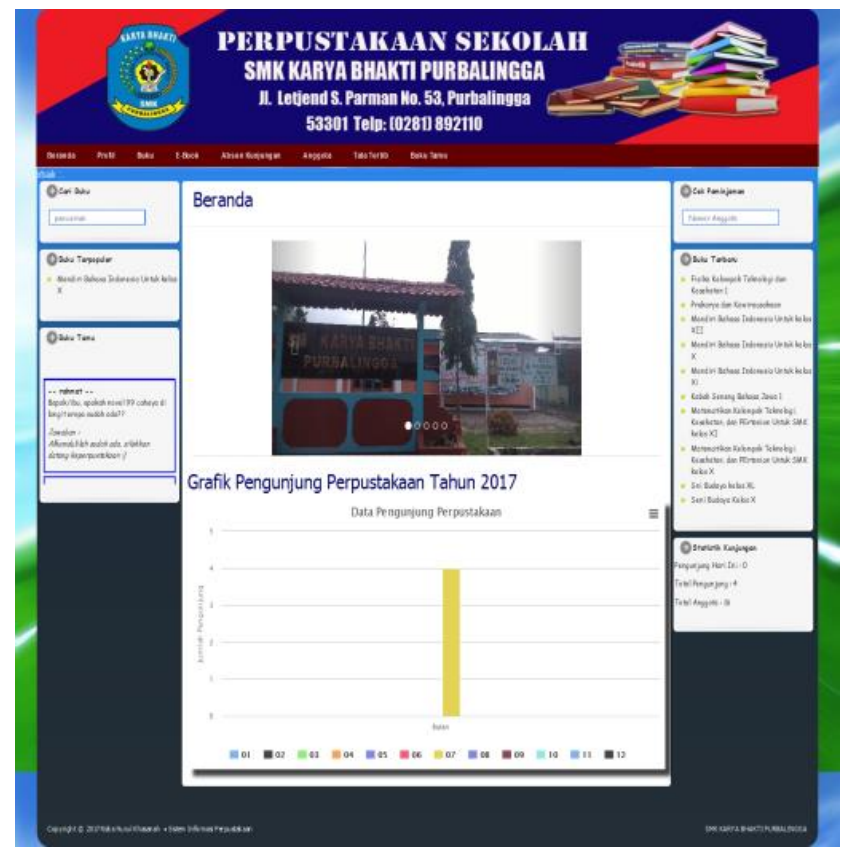

Gambar 8. Halaman Utama Website

\section{Pengujian Unit}

Perancangan perangkat lunak direalisasikan sebagai serangkaian program atau unit program. Kemudian pengujian unit melibatkan verivikasi bahwa setiap unit program telah memenuhi spesifikasinya. 


\section{E. KESIMPULAN}

1. Kesimpulan

Berdasarkan uraian yang telah dibahas pada bab pembahasan maka penulis mengambil kesimpulan terhadap pembuatan Sistem Informasi Perpustakaan Berbasis Web pada, sebagai berikut:

a. Pengolahan data-data di perpustakaan saat ini masih dilakukan secara manual dan belum mempunyai website sebagai sarana penyampaian informasi. Oleh sebab itu penulis membuat sistem untuk mempermudah pustakawan dalam pengolahan data dan membuat website untuk mempermudah dalam penyampaian informasi.

b. Adanya website perpustakaan maka informasi tentang perpustakaan dapat lebih mudah diakses oleh anggota maupun masyarakat dimanapun setelah website ini dipublikasikan.

c. Pada website perpustakaan di lengkapi dengan menu pencarian buku, sehingga mempermudah anggota perpustakaan dalam mencari buku yang di inginkan, serta dilengkapi pula menu cek status peminjaman bagi anggota agar anggota dapat mengingat jangka waktu peminjaman buku tersebut.

d. Adanya website ini juga dapat mempermudah bagi pihak perpustakaan dalam menerima kritik atau saran dari para pengunjung melalui fasilitas buku tamu.

2. Saran

Dari penjabaran kesimpulan diatas, penulis memberikan beberapa saran yang diharapkan dapat membantu agar website ini dapat berkerja secara optimal. Adapun saransaran dari penulis antara lain:

a. Selalu dilakukan pembaharuan data, sehingga informasi yang disampaikan dapat terus disesuaikan dengan perkembangan perpustakaan.

b. Pemeliharaan keamanan terhadap data dan informasi pada perpustakaan perlu diperhatikan dan dijaga agar data tidak bisa diakses oleh orang yang tidak berhak mengaksesnya.

c. Diharapkan untuk mempunyai backup data dimana hal ini dilakukan untuk menghindari hilangnya data secara tiba-tiba.

d. Perawatan terhadap perangkat lunak dan perangkat keras komputer secara berkala agar sistem dapat terhindar dari kerusakan berkala.

e. Penulis menyadari bahwa dalam perancangan website ini memiliki tampilan yang kurang menarik, untuk itu lebih baik diatur kembali komposisi warna dan tata letaknya.

\section{REFERENSI}

A.S Rosa dan M. Shalahuddin. (2013). Perangkat Lunak Terstruktur dan Berorientasi Objek. Bandung: Informatika Bandung.

Kadir, A. (2008). Dasar Pemrograman web dinamis menggunakan PHP (Revisi). Yogyakarta: CV. Andi Offset.

Kadir, A. (2009). Mastering AJAX dan PHP. Yogyakarta: CV. Andi Offset.

Nugroho, B. (2008). Aplikasi Pemrograman Web Dinamis dengan PHP dan MySQL. Yogyakarta: Gava medika.

Paryati dan Yosef Murkaya. KA. (2007). Sistem Informasi. Yogyakarta: Ardana Media.

Puspitosari, H. A. (2010). Membangun Website Interaktif dengan Adobe Creative Suite 5 tingkat dasar. Yogyakarta: PT. Skripta Media Creative.

Saputra, A. (2012). Membuat Aplikasi Absensi dan Kuesioner untu Panduan Skripsi. Jakarta: PT. Alex Media Komputindo.

Sibero, A. F. K. (2013). Web Programming Power Pack. Yogyakarta: Mediakom.

Sigit W., A. (2011). Website Super Canggih dengan Plugin jQuery. Jakarta: Mediakita.

Supriyanto, wahyu dan A. M. (2008). Teknologi Informasi Perpustakaan. Yogyakarta: Kanisius. Retrieved from books.google.co.id/books?isbn=9792119507

Sutopo, A. (2007). Pemrograman Flash dengan PHP dan MySQL. Yogyakarta: Graha Ilmu.

Yakub. (2012). Pengantar Sistem Informasi. Yogyakarta: Graha IImu. 